\title{
Helium isotopic signature in the Ilan Plain, NE Taiwan: geochemical evidences of a magmatic source
}

\author{
AI-TI CHEN ${ }^{1}$, YUJI SANO ${ }^{2}$, CHENG-HONG CHEN ${ }^{1}$, \\ NAOTO TAKAHATA ${ }^{3}$, CHING-HUA LO ${ }^{1}$, TSANYAO \\ YANG $^{1}$, TSUNG-KWEI LIU ${ }^{1}$ AND YUNSHUEN WANG ${ }^{4}$ \\ ${ }^{1}$ National Taiwan University \\ ${ }^{2}$ Kochi University \\ ${ }^{3}$ University of Tokyo \\ ${ }^{4}$ Central Geological Survey, Ministry of Economic Affairs \\ Presenting Author: atchen@ntu.edu.tw
}

The Ilan Plain in northeastern Taiwan, located at the southwestern tip of the Okinawa Trough, is currently undergoing extension and lateral slip. Previous studies suspected that a number of fault and rupture zone exist in this area, and subsurface volcanic materials and igneous bodies may invade the plain as a consequence of the back-arc spreading of Okinawa Trough. With reference to the Kueishantao islet (7.26-8.39 $\mathrm{R}_{\mathrm{A}}$ ) where active volcanic activities in an intracontinental backarc basin of the Ryukyu arc-trench system have been recognized, large amount of fluvial sediments covered on the plain suface may obscure the observations of the tectonic structures. Here we report new noble gas signatures in both water and gas samples from Ilan Plain to evaluate connections of tectonic structures and the mantle source. The dominant component of dissolved air is mixed in varying degree with the crust and upper mantle. By correcting the helium from air-contamination, the helium isotopic ratios in $13 \mathrm{hot} /$ cold spring samples range from 0.16 $2.68 \mathrm{R}_{\mathrm{A}}$, while those in 36 groundwater samples range from 0.03-2.24 $\mathrm{R}_{\mathrm{A}}$. The results from representative sampling sites reveal that the enrichment in mantle input of fluid samples draw a increasing trend from southeast to northwest in the south of assumed E-W Chuo-Shui Fault. Interestingly, this trend partially overlaps the spread of concealed dyke intrusions interpretated by seismic data. Samples from north to the fault mainly show crustal signatures, suggesting dilution of radiogenic helium by thickened sediments relative to the south. In addition, the overall tendency of the helium ratios of samples agrees with the distribution of subsurface heat flow data. Therefore, there might be an influx of thermal energy and silicate material by the heat-mass flow from the mantle into the crust. 